\section{Aggressive Behavior in Online Games and Cybervictimization of Teenagers and Adolescents}

\author{
Elena Aleksandrovna Makarovaa, ${ }^{a}$, Elena Lvovna Makarovab
}

$\begin{array}{ll}\text { Received: } & 4 \text { May } 2019 \\ \text { Revised: } \quad & 19 \text { October } 2019 \\ \text { Accepted: } \quad 22 \text { November } 2019 \\ \text { ISSN: 1307-9298 } \\ \text { Copyright @ IEJEE } \\ \text { www.iejee.com }\end{array}$

DOI: $10.26822 /$ iejee.2019257663

\begin{abstract}
This article discusses the impact of online games on children's lives by violence imposing and manipulation. Online gaming features are highlighted and statistic data are presented based on surveys of Russian teenagers who have been victims of online violence. The research goals are to study reasons for cybervictimization and psychological factors to suggest measures for intervention and prevention violence in the Internet. The subject of research is the role online games play in teenagers' violence development. Methods used are resources analysis, questionnaires and survey, acceptance of self and others scale (W. Fey) and Buss-Durkee inventory for assessing different kinds of hostility. The survey was conducted among 273 young boys and girls aged 14 to 20 years old (schoolchildren and freshmen), equally covering all age categories of both sexes examining teenagers behavior in the virtual space and network communication features. Based on the analysis of resources several principles for intervention, prevention programs development, cybervictimization combating were identified. According to the results of our study, we can conclude that cybervictimization in online games is a really urgent problem, because today's teenagers and adolescents cannot survive without gadgets, so they are vulnerable to online threats, intimidation, manipulation and other kinds of aggression.
\end{abstract}

Keywords: Cybervictimization, Online Games, Violence, Manipulation, Aggression

\section{Introduction}

In the modern world, as many aspects occur in the field of information technology, so many questions arise about the relationship man-computer. The Internet is a huge information bank, the basics of which are very multifaceted, it provides a tremendous opportunity for users, but at the same time it gives unlimited freedom to create information that can harm other people or can be dangerous. Information and communication technologies provide people with means of transforming information into knowledge, contributing to the process of socialization, identity development, and create space for active social interaction and actions, experiment and self-expression in the whole diversity of their manifestations. In the Internet, people can communicate with each other regardless of their gender, social identity, external attractiveness or unattractiveness. All this testifies to the fact that certain communicative barriers cease to exist for interlocutor (Cherkasenko, 2015).

Information and communications technology, the Internet and mobile phones are now a part of teenagers and adolescents' lives. With the development of technology, many psychological phenomena acquire a new context. This also applies to the phenomenon of aggression. Violence, the impulse to death is an integral part of each person, including teenagers and adolescents. "This is part of our animal nature," says French psychologist Jean-Luc Aubert (Aubert, 2001). In the modern world, many aspects occur in the field of information technology, so many questions arise about the relationship man-computer-man. The Internet is a huge information bank, the basics of which are very multifaceted; it provides a great opportunity for users not only for work, but also for entertainment. However, at the same time it gives unlimited freedom and opportunities to create information that can not only be misleading and incorrect, but also be dangerous harm and other people.
The role of cybervictimization was discussed in researches in the fields of psychology, sociology and education, in which it was proven that adolescents are more likely to experience greater distress from cyber threats than from traditional bullying.

Cybervictimization risk studies cover social, demographic, psychological, family, educational and technological factors. Most of the results obtained are contradictory, especially for age and gender. More consistent results are observed regarding psychological factors (self-esteem and social anxiety are associated with the likelihood of cybervictimization). As in case of teenagers and adolescents, the risk of victimization reveals a correlation with the intensity of the use of the Internet and the specifics of virtual interaction. Adolescents who actively participate in online games are more prone to victimization from online violence (Kowalski et al., 2014). Due to the almost endless possibilities of reaching the users, the victim of cyberbullying does not know how many people are involved in harassment. The audience to which messages are distributed may be almost unlimited. It is publicity that is one of the most significant factors associated with the experience of distress in adolescents.

Internet online games have become a subject of interest for psychologists, since dependence on them is an element worthy of further consideration. Internet online games have been the subject of considerable research, with the result that two opposing opinions have arisen about the negative effects compared with the positive effects of this type of games. One point of view is that participation in online gaming using violent content increases the players' level of hostility and cruelty. Other point of view is that such games can be a valuable educational tool, and gamers benefit from communicating with other players. This research summariz- 
es the results of different studies that examined the impact of violent content of Internet games on the level of aggression among teenage gamers, and also presents the proposed assessment and methods to combat it.

As in online games people can communicate with each other anonymously or using a fake identification, they feel no restrictions, no moral or ethic limitation, so they can be abusive, use obscene vocabulary and do not have to hide aggression and evil intent. In this regard, we can talk about surrogate communication in online games. Education, culture, socialization help to "tame" aggression in real life, but with the change in the rules of online game, the problem of violence becomes more acute. In the world of games, social rules and frameworks change quite significantly: the institute of the family, school and society are undergoing serious transformation. The phenomenon of aggression takes on new forms, such as cybervictimization, based on the complex structure of interactions between the gamers. Often bullies in virtual space do not identify themselves as pursuers (Howlett-Brandon, 2014). What some people understand as a violation of the norms of communication, others may not perceive as such. The perception of risk is a fundamental factor in the acquisition and maintenance of actions related to cybersecurity, mainly as a shield against present dangers; those associated with unsafe behaviour in which minors incur voluntarily (Catalina et al., 2014). The researchers are in agreement in pointing out that access to the Internet offers an infinite number of opportunities, but at the same time, exposure to risks is also greater (Kowalski et al., 2014), especially the risk of cyber-aggression or cybervictimization. It is well known that children are mostly merciless, unburdened by high moral principles. Therefore, they often victimize classmates because they can do this. Having matured, such aggressors often repent and even look for an opportunity to apologize to the victim. Others justify their own behavior, believing that the victimized peer "asked for it". Researchers identify two main factors provoking bullying in the school team:

1. Improper family education. Many aggressors are either brought up in families where corporal punishment is used on a regular basis or taught to protect themselves against bullies using brute force. Parents are convinced that the child should be able to stand up for themselves, but they are too zealous in their desire to raise a tough guy or girl. Another type of aggressor is a child leader, who seeks to manage the team according to his

2. Teachers' misunderstanding. Sometimes teachers unintentionally provoke harassment, highlighting the negative traits in a particular child. But more often, teachers simply do not notice the beginning of bullying due to "pedagogical blindness". There is some kind of connivance on the part of the teaching staff.

Victim's physical or mental impairment is not necessarily the cause of harassment or the source of the behavior problem. Handicapped children are not to blame. Absolutely any child can be found guilty if you are looking for flaws, but this does not mean they should be pursued and bullied (Onur, 2017).

In 2006, a group of experts from the US formulated the nature and extent of e-aggression and discussed recommendations for addressing this issue by public health organizations, including considering proposals for future research (Ybarra, et al., 2006). They discussed the problem of cybervictimization (for example, offensive experiences in the Internet due to bullying, sexual harassment, disaster, etc.) reported by young people. Risky online behaviors are becoming the norm for teenage Internet users (Ybarra, et al., 2007). The nature and extent of violence in the youth environment and aggression is seen in healthy, sensible people. The purpose of this study is to improve the health of adolescents, to prevent diseases caused by victimization, also physical and mental health problems and suicidal attempts associated with unintentional injuries, violence in the net, etc.

Teenagers use social networks such as MySpace, Facebook, VKontakte and other sites to be connected and to communicate with peers, they also participate in online games to be the a member of some team, some social group. For example, interacting with classmates online, blogging, publicizing, browsing online diaries, exchanging instant messages (IM), text messaging, chatting, e-mailing, sharing videos help teens to stay in touch with friends, to make new friends, to flirt with other sex and make plans for the future. There is a certain concern about the negative pressure that leads to Internet threats that may lead underestimation of one's abilities, inferiority complex, and poor state of physical, mental and social health.

Also nowadays, it has become quite popular to exercise manipulation and distribute fake information with the help of "trendy" social networks. What is manipulation? What is it used for? Manipulation is the imposition of one's will in the form of a hidden psychological influence by a manipulator. The basis of manipulation is human emotions' mistreatment. Social networks help transmit manipulation actions "uncensored", publish them instantly and quickly distribute them within the net. Moreover, it is much more difficult to distort or make it stop distributing any information in the Internet than in any other modern media. Not all forms of cybervictimization are recognized as such by respondents of the surveys. In recent years, there has been a surge of interest to cybervictimization (Whittaker, Kowalski, 2015). Some researchers are increasingly talking about a special "cyberbullying culture" (Vandebosch, Van Cleemput, 2009) and even call it a "disease of the 21st century" (Chisholm, 2014).

All the researchers come to a conclusion that a new phenomenon of Internet communication - cybervictimization, has become a distinct social problem and needs to be discussed and researched in order to better understand the phenomenon and to develop a certain preventive program.

Our research is not a pioneering study as a lot of works both by Russian (Andreeva, 2015 ; Baranov, Rozhin, 2015; Cherkasenko, 2015; Berezina, 2015; Makarova, 2016) and European researchers (Brush, 2014; Hester, 2012; Van Ingen, 2014) have been already published devoted to the problem of cyberbullying, violence in online communication and cybervictimization.

\section{Method}

Categories for Methodological Study

\section{Violence in cyber space}

Violence in cyber space is understood as a certain kind of harassment, cybervictimization, defined as deliberate aggressive actions, systematically carried out for a certain time by a group of people or an individual using electronic forms of interaction and directed against the victim, who cannot defend himself (Bastiaensens et al., 2014). Most often, the aggression appears in studies as a single category. However, in a number of works different types of aggressive behavior are distinguished and their specificity in a virtual environment is analyzed. K.C. Runions (Runions, 2013) considers four forms of cyberbullying according to two dimensions: self-control and affective violence. The most common is the distinction between reactive and instrumental aggression. If the first arises as a reaction to frustration, the second type is intentionally planned behavior that uses aggression to achieve a certain goal. Reactive aggression is associated with negative emotions (anger, fear) and is aimed at reducing them. Exciting motives are dealing with positive emotions that a person receives from 
aggressive behavior. The combination of two dimensions provides a scheme of four types of aggressive behavior: impulsive-reactive, controlled-reactive, controlled-exciting, impulsive-exciting.

\section{Impulsive-reactive aggression}

Impulsive-reactive aggression arises as a reaction to frustration and is characterized by an impulsive response to a threat. It involves two processes: the activation of a hostile scheme and the violation of self-control. Attribution of hostile intentions is particularly sensitive to the uncertainty factor characteristic of the Internet. Online interactions are characterized by the incompleteness of semantic signals due to the absence of non-verbal, paralinguistic signs. Incomplete information can increase uncertainty, which in turn can lead to more likely attribution of hostile intentions. But the activation of a hostile scheme is not enough for impulsive aggression. The second component is low self control. In addition to individual traits, situational factors, such as fatigue, lack of sleep, are important for self-control, which is important for adolescents who stay behind the monitor after midnight. In addition, the Internet provides the ability to instantly ease stress (because the special chronotope of the Internet allows sending messages at any time, as soon as the need arises).

\section{Controlled-reactive type of aggressive behavior}

Controlled-reactive type of aggressive behavior associated with the control of attention, the possibility of suppressing anger and impulsive reaction and the accumulation of aggression. This type is characterized by high self-control in situations of provocation, thus avoiding an immediate aggressive response. Sometimes anger and desire for retribution subside over time. However, the processes of rumination ("rethinking" of the incident) can lead to a delayed impulsive reaction or controlled reactive aggression. One of the key features of information technology is the constant fixation of digital information. Traumatic data remain in the network forever. Constant appeal to it heats the rumination, which in turn increases the likelihood of aggression. This type of aggressive behavior is associated with a special form of cyberbullying, in which adolescents who are victims of traditional bullying and other forms of aggression use the Internet to revenge and dispense justice (König, 2010).

\section{Controlled agitating aggression}

Controlled agitating aggression is intentional, planned behavior is aimed at achieving goals (for example, improving social status) and using violence as a means. Cyber bullies belonging to this category more often consider themselves to be experts in information technologies and are proud of their "achievements" in cyberbullying, in using technological, communication and social skills in cyber-aggression. The bully may be well aware of the existing moral standards, but this does not stop harassment. This behavior is associated with impaired empathy and moral consciousness (Fedunina, 2015).

\section{Impulsive aggression}

The motive for this type of cyber-aggression is striving for immediate experience of excitement, joy, pleasure, as well as overcoming routine and boredom. It is listed as one of the most common motives (Compton et al., 2014). No wonder many offenders justify their aggressive actions, saying that they simply had fun and did not want any harm done. The Internet is becoming a search space for new exciting experiences, thrills in the field of interpersonal relationships. Anonymity and distance lead to an underestimation of the seriousness of what is happening and the difficulty of an- ticipating the consequences of their behavior. This type is often characterized by the absence of a formed intent to cause harm and the predominance of the motive of entertainment. In the absence of social signals that could reinforce the empathic reaction (both emotional and cognitive), young people may believe that their jokes and comments fit into the norms of what is permissible and just funny.

\section{Methodology of Cybervictimization Identification}

The main purpose of cybervictimization is the deterioration of the emotional sphere of the victim and / or social relations destruction. Cybervictimization includes a range of different forms of behavior, from playful or friendly teasing to threats, insults or even psychological virtual terror, all of them causing stress, depression or even suicide.

\section{Facts and Analysis of Resources}

Facts that prove that cybervictimization is indeed a serious problem to consider are:

1. Teenagers and adolescents have certain experience with traditional bullying at school or neighborhood before they face challenge related to cyber space, so they can use this experience against their rivals,

2. Teenagers and adolescents show a higher prevalence of threats and violence related to bullying using the Internet (for example, social networks, Skype, instant messaging, online games, etc.) than adults who prefer using cell phones for these purposes (for example, text messages, photos, video, etc.),

3. Negative relationships exist between children and parents related the Internet use for cybervictimization, because parents notice that something is disturbing their children, they notice that their physical and psychological health is changing. Teenagers usually protect their privacy by hiding phones, putting passwords on a computer and changing passwords to social networks.

American scientists have identified three features of cybervictimization and called them the principle of the three "A" - anonymous, accessible, affordable (anonymity of the Internet, accessibility of social networks and online games and low price for participation). Anonymity in online games makes cybervictimization much easier for the offenders, since they cannot be identified and do not see the emotional response of the victim. The offender is not always aware that a real people read messages and their feelings are hurt. The offender sees it as a part of the game and the victim is just an opponent (rival) in the game. Thus, we can say that the real life is replaced with the virtual one, in connection with this fact communication can be distorted on both sides. The availability of the Internet has become almost ubiquitous, and thanks to mobile devices and wireless networks, the user gets the opportunity to communicate in social networks 24 hours a day, 7 days a week. This allows the gamer to either interrupt the main activity (school or work) or to distract from it. Most often, teenagers and adolescents of school age who are addicted to online gaming often fall under the influence of their peers or classmates (peer pressure) and become victims of cyber violence.

\section{Principles of Combating Cybervictimization}

Based on the analysis of resources and our own study, we identify the following principles of combating cybervictimization: 
- to organize the widespread introduction of training programs for law enforcement officials, school teachers and parents of teenage children. Courses, seminars and conferences should inform those interested in this problem about the essence of cyber threats and measures to combat them;

- to develop software services that will allow to control and prevent the distribution of malicious content, to quickly identify those who violate the law when using the Internet;

- to provide users with appropriate tools and technologies. Any user should know the telephone number of the hotlines, own tools with which you can report the illegal behavior of other users;

- to create of a rapid response system for content and service providers, telecom operators, law enforcement agencies on the illegal activities of the Internet.

For preventing cyberbullying, teenagers should not share their personal information; should not share their page with strangers; keep track of information posted online; should not send messages with images that may offend someone; should not post embarrassing pictures or videos of themselves.

The analysis of victimization factors is associated with the development of preventive programs aimed mainly at developing social skills, increasing self-esteem and reducing social anxiety. For example, a program can be aimed at increasing the power of the ego, the ability to preserve identity, emotional stability, critical thinking and purposeful behavior in situations of stress and emotional confusion. The study shows that this kind of competence can help potential victims of cyberbullying to cope with dangerous social situations. Brochures and tutorials for teens are being actively developed that teach them how to protect their personal information in the net and how to cope with cyberbullying. Many brochures use real or typical stories of teenagers who have been victims of cyberbullying, as well as their experience in coping with this problem. Fiction related to the phenomenon of cyberbullying, as well as scripts and theatrical performances of adolescents, also helps.

\section{Data Collection Tools}

An adapted questionnaire on school aggression Buss - Durkee Hostility Inventory (BDHI) (Buss, Durkee, 1957), standardized by A.A. Khvan, Y.A. Zaitsev and Y.A. Kuznetsova (Khvan et al., 2006), the purpose of which is to determine the level of aggressiveness of schoolchildren in an educational institution. Under aggressiveness refers to the property of the person, characterized by the presence of destructive tendencies, mainly in the field of subject-object relations. The survey was conducted anonymously, socio-demographic aspects included age, gender, socio-economic situation, the nature of the institution (private or public) and others.

The questionnaire consists of 36 points with two possible answers - "yes" and "no". Respondents must answer questions that are formulated in such a way as to most lessen the influence of public approval of the answer to the question.

As a result, differentiating manifestations of aggression and hostility were identified in the form of the following reactions. Questionnaire questions are divided into eight factors and are evaluated on 8 scales:

1. Physical aggression - the use of physical force against another person.

2. Indirect - aggression, in a roundabout way directed at another person or not directed at anyone.
3. Irritation - readiness for the manifestation of negative feelings at the slightest excitement (short temper, rudeness).

4. Negativism is an oppositional manner in behavior from passive resistance to active struggle against established customs and laws.

5. Offense - envy and hatred of others for real and imaginary actions.

6. Suspiciousness ranges from mistrust and caution towards people to the belief that other people plan and cause harm.

7. Verbal aggression - the expression of negative feelings through the form (cry, squeal), and through the content of verbal responses (curses, threats).

8. Guilt - expresses the subject's possible conviction that he is a bad person, that evil is doing, as well as remorse of conscience felt by him.

This technique shows that aggression, as a property of a person, and aggression, as an act of behavior, can be understood in the context of a psychological analysis of the motivational-need sphere of a person. Therefore, the Bass-Darki questionnaire should be used in conjunction with other techniques, in our study it was Acceptance of Others Scale (Fey, 1954), designed to diagnose the level of acceptance of other people, especially among schoolchildren and first-year students. The questionnaire was applied by a research team during the school day of participating schools.

\section{Data Collection}

The questionnaire was used in educational institutions in which there was a written consent of the director of the institution and the parents. The data were processed using the program (Table 1).

Table 1. Acceptance of Others Scale questionnaire results (William F. Fey)

\begin{tabular}{lcccc}
\hline $\begin{array}{l}\text { Gender and } \\
\text { age correlation }\end{array}$ & High & $\begin{array}{r}\text { Medium with } \\
\text { tendency to } \\
\text { high }\end{array}$ & $\begin{array}{r}\text { Medium with } \\
\text { tendency to } \\
\text { low }\end{array}$ & Low \\
\hline $\begin{array}{l}\text { Females } \\
\text { (20 years old) }\end{array}$ & 9 & 33 & 46 & 12 \\
\hline $\begin{array}{l}\text { Males } \\
\text { (20 years old) }\end{array}$ & 28 & 41 & 23 & 8 \\
\hline $\begin{array}{l}\text { Females } \\
\text { (18 years old) }\end{array}$ & 38 & 36 & 20 & 6 \\
\hline $\begin{array}{l}\text { Males } \\
\text { (18 years old) }\end{array}$ & 41 & 39 & 17 & 13 \\
\hline $\begin{array}{l}\text { Females } \\
\text { (16 years old) }\end{array}$ & 16 & 37 & 33 & 14 \\
\hline $\begin{array}{l}\text { Males } \\
\text { (16 years old) }\end{array}$ & 19 & 42 & 22 & 17 \\
\hline $\begin{array}{l}\text { Females } \\
\text { (14 years old) }\end{array}$ & 11 & 26 & 44 & 19 \\
\hline $\begin{array}{l}\text { Males } \\
\text { (14 years old) }\end{array}$ & 7 & 38 & 29 & 26 \\
\hline
\end{tabular}

First, we obtained calculations of the frequency of all socio-demographic questions, elements of the Fey scale, as well as the percentage of answers, the mean and standard deviation of each of the options.

Secondly, the link between violence using ICT (cyberbullying) and traditional bullying, for which the Pearson correlation 
between factor 8 (violence using ICT) and the other factors of the questionnaire was calculated, was processed. In addition, for each factor, mean and standard deviations were calculated to determine the most common types of aggression.

\section{Findings and Results}

Diagnostics of the experiment on the survey among 263 young boys and girls aged 14 to 20 years old (school children and University freshmen), equally covering all age categories of both sexes examining behavior of adolescents and teenagers in the virtual space and the features of the network communication was conducted in 2018 in the city of Taganrog, Russia. At this initial stage of the experiment, 135 pupils from senior secondary schools in the city of Taganrog and 128 first-year college students at the Taganrog Institute of Management and Economics were the participants. The experiment involved $48.15 \%(n=65)$ of schoolgirls and $51.85 \%(n=70)$ of schoolboys; $42.97 \%(n=55)$ of student girls and $57.03 \%(n=73)$ of student boys. Most subjects were from 14 to 20 years old (Table 2-5).

Table 2. Verbal bullying location among teenagers and adolescents

\begin{tabular}{|c|c|c|c|c|c|}
\hline $\begin{array}{l}\text { Gender and } \\
\text { age correla- } \\
\text { tion } \\
\end{array}$ & Classroom & Playground & School & Street & Internet \\
\hline $\begin{array}{l}\text { Females } \\
(n=55) \\
\text { ( } 20 \text { years old) }\end{array}$ & 51 & 0 & 27 & 4 & 18 \\
\hline $\begin{array}{l}\text { Males } \\
(n=73) \\
(20 \text { years old })\end{array}$ & 30 & 11 & 2 & 28 & 29 \\
\hline $\begin{array}{l}\text { Females } \\
(n=21) \\
\text { (18 years old) }\end{array}$ & 34 & 8 & 32 & 16 & 10 \\
\hline $\begin{array}{l}\text { Males } \\
(n=24) \\
(18 \text { years old })\end{array}$ & 39 & 4 & 32 & 15 & 9 \\
\hline $\begin{array}{l}\text { Females } \\
(n=22) \\
(16 \text { years old) }\end{array}$ & 34 & 11 & 11 & 11 & 33 \\
\hline $\begin{array}{l}\text { Males } \\
(n=23) \\
(16 \text { years old })\end{array}$ & 19 & 12 & 18 & 13 & 38 \\
\hline $\begin{array}{l}\text { Females } \\
(n=22) \\
(14 \text { years old })\end{array}$ & 35 & 3 & 35 & 8 & 19 \\
\hline $\begin{array}{l}\text { Males } \\
(n=23) \\
\text { (14 years old) }\end{array}$ & 26 & 4 & 21 & 22 & 27 \\
\hline
\end{tabular}

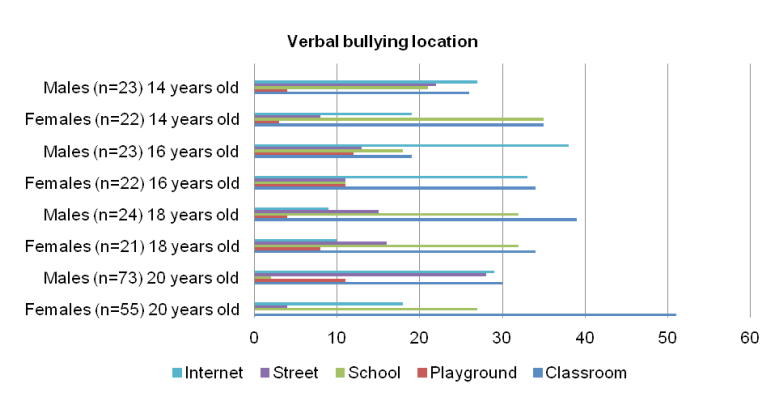

Figure 1. Verbal bullying location among teenagers and adolescents
Table 3. Physical bullying location among teenagers and adolescents

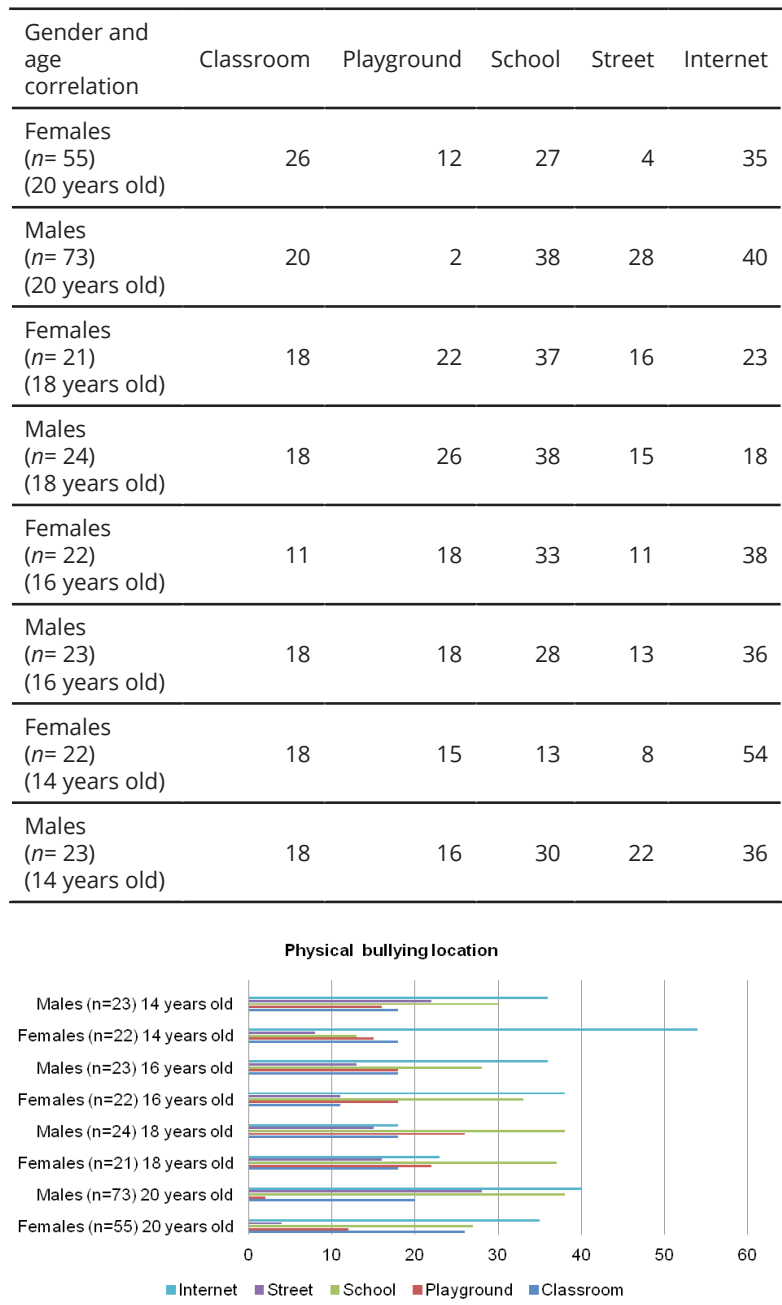

Figure 2. Physical bullying location among teenagers and adolescents

Table 4. Verbal bullying frequency among teenagers and adolescents

\begin{tabular}{lcccc}
\hline $\begin{array}{l}\text { Gender and age } \\
\text { correlation }\end{array}$ & Often & Sometimes & Once & Never \\
\hline $\begin{array}{l}\text { Females }(n=55) \\
(20 \text { years old })\end{array}$ & 5 & 32 & 45 & 18 \\
\hline $\begin{array}{l}\text { Males }(n=73) \\
(20 \text { years old })\end{array}$ & 9 & 45 & 18 & 28 \\
\hline $\begin{array}{l}\text { Females }(n=21) \\
(18 \text { years old })\end{array}$ & 13 & 37 & 31 & 19 \\
\hline $\begin{array}{l}\text { Males }(n=24) \\
(18 \text { years old })\end{array}$ & 4 & 35 & 38 & 23 \\
\hline $\begin{array}{l}\text { Females }(n=22) \\
(16 \text { years old })\end{array}$ & 7 & 30 & 44 & 19 \\
\hline $\begin{array}{l}\text { Males }(n=23) \\
(16 \text { years old })\end{array}$ & 7 & 47 & 20 & 26 \\
\hline $\begin{array}{l}\text { Females }(n=22) \\
(14 \text { years old })\end{array}$ & 17 & 45 & 23 & 15 \\
\hline $\begin{array}{l}\text { Males }(n=23) \\
(14 \text { years old })\end{array}$ & 11 & 50 & 23 & 16 \\
\hline
\end{tabular}




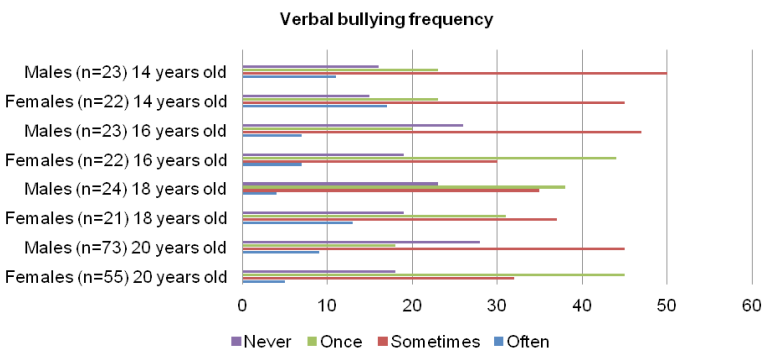

Figure 3. Verbal bullying frequency among teenagers and adolescents

Table 5. Physical bullying frequency among teenagers and adolescents

\begin{tabular}{lcccc}
\hline $\begin{array}{l}\text { Gender and age } \\
\text { correlation }\end{array}$ & Often & Sometimes & Once & Never \\
\hline $\begin{array}{l}\text { Females } \\
(n=55) \\
(20 \text { years old })\end{array}$ & 0 & 9 & 14 & 77 \\
\hline $\begin{array}{l}\text { Males } \\
(n=73) \\
(20 \text { years old })\end{array}$ & 0 & 9 & 18 & 73 \\
\hline $\begin{array}{l}\text { Females } \\
(n=21)\end{array}$ & & & & \\
$(18$ years old $)$ & 2 & 4 & 20 & 74 \\
\hline $\begin{array}{l}\text { Males } \\
(n=24) \\
(18 \text { years old })\end{array}$ & & & & \\
\hline $\begin{array}{l}\text { Females } \\
(n=22) \\
(16 \text { years old })\end{array}$ & 0 & 11 & 23 & 66 \\
\hline $\begin{array}{l}\text { Males } \\
(n=23) \\
(16 \text { years old })\end{array}$ & 4 & 4 & 7 & 85 \\
\hline $\begin{array}{l}\text { Females } \\
(n=22) \\
(14 \text { years old })\end{array}$ & 13 & 20 & 40 & 27 \\
\hline $\begin{array}{l}\text { Males } \\
(n=23) \\
(14 \text { years old })\end{array}$ & 13 & 13 & 29 & 45 \\
\hline & & 4 & 24 & 71 \\
\hline
\end{tabular}

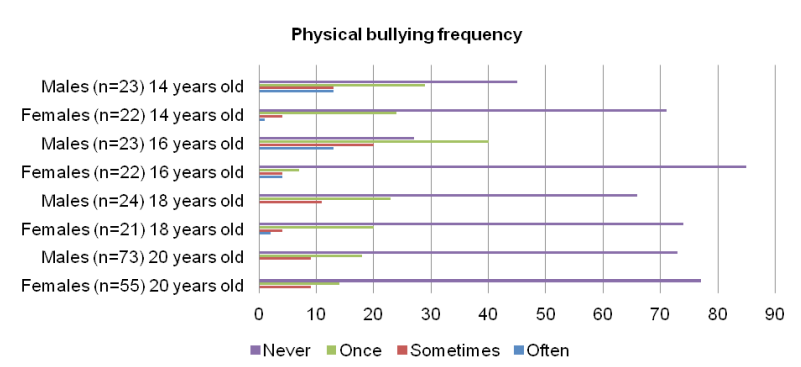

Figure 4. Physical bullying frequency among teenagers and adolescents

According to the questionairy results, different manifestations of aggression and hostility were identified: physical and verbal forms of aggression. Physical aggression is the use of physical force against another person. As for traditional forms of school bullying they can be encountered in the street, in a classroom, in different parts of school building, in the school yard and playground, in the street and even at home. Verbal aggression is typical for most places where children and adolescents spend their time and also it is encountered in the social networks and online games. Verbal aggression is the expression of negative feelings through the form (yelling, squealing, shouting), and through the content of verbal responses (curses, threats, offensive nicknames and even abusive language which is taboo for most children and adolescents). Verbal cyber-bullying (i.e., bullying in the Internet environment) has become a growing form of social aggression because it uses the anonymity of the Internet, its incredible speed of information spreading and impunity for the perpetrator. Anonymity places bullies at an unfair advantage over their victims, technological skills paired with social anonymity facilitates social aggression in social networks and online games.

As for the frequency of physical and verbal aggression, over $80 \%$ of the examined males and females have never faced physical bullying in reality, but from 30 to $50 \%$ of both males and females have experienced verbal bullying in virtual world, i.e., in social networks, online gaming and while communicating with peers via E-mail.

Among verbal forms of aggression we can identify negative comments exchange, personally or in social group, insulting or unauthentic posts, fake information and facts, embarrassing photos or videos with compromising information or content, denigration presenting false and derogatory information to others, impersonation, which occurs when the perpetrator poses as the victim and conveys hurtful messages to others.

In the survey conducted, adolescents reported using a computer and / or other electronic device from 1 to 3 hours per day $(79.5 \%, n=209)$, and also state that they have their own mobile phone $(98.1 \%, n=253)$. The survey results are shown in Figure 5 \& Figure 6.
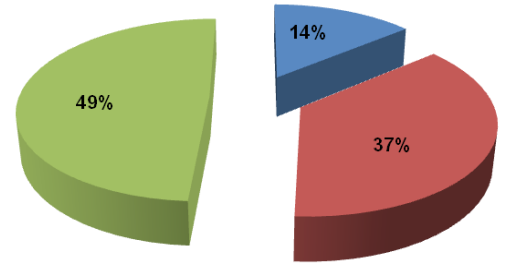

victims of cybervicinization $(n=37)$

- witnessed cyberbullying $(n=97)$

- participated in cybervictimization $(n=129)$

Figure 5. Participation in cybervictimization

According to the survey, among teenagers and adolescents between the ages of 14 and 20 who used the Internet, only $14,07 \%(n=37)$ admitted they were victims of cybervictimization in online games or other activities in cyber space, 36,88\% ( $n=$ 97) of respondents witnessed cyberbullying (victimization and harassment in the network), $49,05 \%$ ( $n=129)$ confirmed that they participated in cybervictimization as a part of a group or individually.
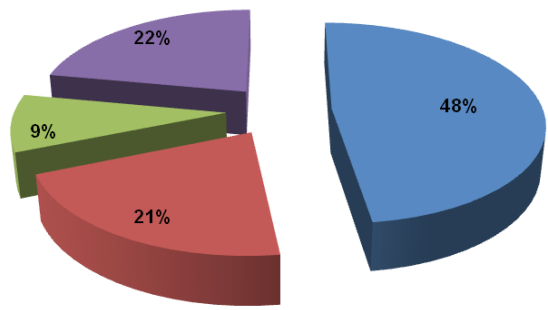

- appearance $(\mathrm{n}=126)$ -nationality or religion $(n=55)$ - gender $(n=24)$ - physical or mental inability $(n=58)$

Figure 6. Reasons for cybervictimization

The reasons for cybervictimization mentioned by the interviewed teenagers and adolescents of school age were: appearance $-47,91 \%(n=126)$, nationality or religion $-20,92 \%$ $(n=55)$, gender $-9,12 \%(n=24)$, physical or mental inability $22,05 \%(n=58)$.

\section{Discussion}

We believe these are not the real reasons for cybervictimization, but rather the way adolescents try to establish themselves by insulting or humiliating each other, paying particular attention to weaknesses of their victims. The real reasons for cybervictimization are the following: 
1. Striving for excellence. This is an innate feeling and human beings will never get free of it, because this striving is the result of evolution. This process begins at the age of five, when a life purpose is formed as well as the focus of children's aspiration. Later in life it becomes a source of motivation, organizing life and giving it a certain meaning. Excellence can be achieved by taking negative and positive steps. The positive one takes into account the well-being of other people and the desire to assist in its achievement. The negative one is inherent in selfish people with weak ability to adapt, who struggle for superiority with anti-social or even deviant behavior. An example of striving for excellence in adolescents is their struggle for social status of a leader or superior position in a peer group.

2. The sense of inferiority, or inferiority complex - a set of psychological and emotional sensations of a person, expressed in the sense of their own inferiority and irrational belief in the superiority of others.

3. Envy is the same as hidden rivalry; teenagers seek to win, but compete inside themselves, scoring even when the imaginary rival does not suspect it.

4. Revenge - actions taken from the prompting to respond adequately to real or imagined injustice caused earlier. Revenge begins with a fit of indignation, similar to an internal explosion, which is caused by unexpected and unfair events or attitudes towards them.

5. Cybervictimization in games or entertainment can start with a regular joke, but jokes may be different, some people's jokes may be harmless, contributing everyone's mood, so to speak without victims, others ironically trick people around, not seriously offending anyone, and the third sort of people are being sarcastic in their jokes, the object of such humor is not a joke. Humor is a way to elevate oneself, because the object of laughter is ridiculous, and the subject of a joke is considered witty. Laughing at other people is considered to be self-elevating at the expense of others.

\section{Conclusions}

Thus, according to the results of our study, we can conclude that cybervictimization in online games is a really urgent problem, because today's teenagers and adolescents are the information generation and cannot survive without gadgets, laptops, navigators and cell phones for a minute. Also, with the help of social networks and the Internet, intimidation, manipulation, victimization and threats sneak among teenagers and adolescents who cannot stand up for themselves. It is necessary to take measures to solve this problem and take precautions that will help teenagers and adolescents who surf the Internet every day not to fall victims to cyber threats. Studies show that victimization due to cyberbullying can have the most serious consequences for the health of young digital users and can lead to depression, anxiety and even suicidal behavior. Victims of cyberbullying have lower rates of physical and mental health, are more likely to show a tendency to psychosomatic problems, delinquent and aggressive behavior, social anxiety. The risk of mental disorders in cyberbullying victims is considered in the context of risk factors for the development of mental and physical disorders due to trauma and stress.

A person, who becomes a victim of cyberbullying, faces a challenge and undergoes mental changes, nervous system break. The consequences of this can be very deplorable, up to serious mental illnesses.
It is assumed that experimental results can contribute to both empirical research and cybervictimization prevention programs. A more differentiated view on cybervictimization can not only deepen our understanding of this phenomenon, but also allow developing more effective preventive programs.

Today two main areas of victimization research can be identified: identifying risk factors and describing the impact of cybervictimiztion on teenagers and adolescents. Almost any publication on cybervictimization directly or indirectly addresses the issue of negative impact, but there are not enough empirical studies that would research the peculiarities of the psychic reality of adolescents who resort to interpersonal aggression on the Internet, not just state its behavioral manifestations. A more profound study of this phenomenon is needed. What are the psychosocial characteristics and perceptions of cyberbullying associated with each type of cyber-aggression? Are there any sociodemographic differences in the prevalence of different types of cybervictimization? How effective can general preventive strategies for cybervictimization be?

It is generally recognized that victims of cyber-aggression can easily become aggressors, and the observer (by-stander) can easily become a pursuer by joining the persecution and supporting the bully by simply pressing the "forward" or "I like" message that degrades another person. However, research is needed that would provide a more differentiated picture of these processes.

Intervention and prevention programs against bullying have had positive results regarding reduction of victimization rates but not in terms of perpetration rates. From the point of view of Psychology, it is essential to understand the adversary to resolve any conflict. In this connection, in order to predict cyberbullying and to introduce preventive actions, it would be necessary to take into account personal and social variables of those adolescents who perpetrate cyberbullying. Most studies have considered the victims' point of view, and just a few have focused on analyzing cyberbullies. For this reason, we believe more studies are necessary that would focus on cyberbullies specifically, also on witnesses' (watchers) profile and relationship.

To stop cyberbullying is possible and necessary. Psychologists can not prescribe how to stop victimization and bullying in each particular situation at school. But it is important to take into consideration that in most cases we are talking about mobbing or collective harassment, in this case it is impossible to solve the problem in the "victim-aggressor" plane. Classmates, even if they are not directly involved in bullying, and teachers are also involved in this process, so it is necessary to work with them. The main and the only possible way to stop the harassment is to create a psychologically healthy atmosphere in the team.

As a solution to the problem joint activities that unite the entire class, teamwork on a common project, team building through extracurricular activities should be considered. But for these activities to be successful, the support of a qualified psychologist and the active involvement of teachers is required.

The most important step is letting children understand that harassment, aggression, mockery, are not harmless fun, but a serious problem with not less serious consequences. Adults should indicate that they have noticed the actions of the aggressors and intend to stop them.

Addiction to social networks and online games is a problem of modern life, especially for children and adolescents. Moreover, they depend on the Internet in their school studies, so it is important to make the cyber space safe and secure and to teach children how to deal with those who create dangerous 
situations in and around the Internet environment and how to avoid cybervictimization. An important practical activity is raising adults' awareness. Many adults of the current generation (parents and teachers) are not aware of the diverse potential of the Internet to the same extent as their children and schoolchildren. An obvious measure is introduction of anti-bullying strategies and methodologies to teachers in order to combat bullying at schools; as well as lecturing, providing information and practical training classes to parents and recommendations to children and adolescents for them to be ready to face a perpetrator and fight back.

The results obtained in the study will allow creating a preventive program, which should be based on the ideas of team building and support, should be characterized by the individualization of educational activities, and involve all the participants in the educational environment. It should also be a scientifically-based, planned and purposeful system of interaction between schoolchildren, teachers and parents. Such a preventive program should become not only socially significant, but also a psychologically necessary event, as the psychological and pedagogical support of potential participants of bullying (either traditional or cyberbullying) will create conditions for self-awareness of children and adolescents not only in the educational environment, but in the cyber space as well.

\section{Acknowledgements}

The current study is supported by RFBR project № 18-292209X.

\section{References}

Andreeva, A.O. (2015). Internet manipulation. Information Security and Prevention of Cyber Extremism among Youth. - 21-28.

Aubert, J-L. (2001). La violence dans les ecoles. Paris: Odile Jacob. 208 p.

Baranov, A.A., Rozhina, S.V., (2015) Psychological analysis of the causes of adolescent cyberbullying. Bulletin of the Udmurt University - № 3. - 5-8.

Bastiaensens, S., Vandebosch, H., Poels, K., Van Cleemput, K., DeSmet, A., De Bourdeaudhuij, I. (2014) Cyberbullying on social network sites. An experimental study into bystanders' behavioural intentions to help the victim or reinforce the bully. Computers in Human Behavior, 31(1), 259-271. https://doi.org/10.1016/j. chb.2013.10.036

Berezina, O.S. (2015) Social prevention of cyberbullying among teenagers. Information Security and Prevention of Cyber Extremism among Youth. - 63-67.

Brush, S. R.G. (2014) Cyberbullying: Characteristics, administrators' responsibilities, and effective communication strategies. United States: Ann Arbor. 122 p.

Buss, A. H. \& Durkee, A. (1957). An inventory for assessing different kinds of hostility. Journal of Consulting Psychology, 21, 343-349. http://dx.doi.org/10.1037/ h0046900

Catalina, B., Lopez-de-Ayala, M.C., \& Garcia, A. (2014) Los riesgos de los adolescentes en Internet: los menores como actores y victimas de los peligros de Internet. Revista Latina de Comunicacion Social, 69, 462-485. https://doi.org/10.4185/RLCS-2014-1020
Cherkasenko, O.S. (2015). Social network as a kind of social communication. Materials of the 36th international conference: issues of pedagogy and psychology. №3. - p. 141.

Cherkasenko, O.S. (2015). The phenomenon of cyberbullying in adolescence. Personality, family and society: issues of pedagogy and psychology.- № 6. - 52-54.

Chisholm, J.F. (2014). Review of the status of cyberbullying and cyberbullying prevention. Journal of Information Systems and Education, 25(1). 77-87.

Compton, L., Campbell, M.A., Mergler, A. (2014). Teacher, parent and student perceptions of the motives of cyberbullies. Social Psychology of Education, 17, 383400. https://doi.org/10.1007/s11218-014-9254-x

Fedunina N.Y. (2015). Representations of the triad "The pursuer - the victim - the observer" in cyberbullying in English literature. Psychological studies. 8(41). p.11.

Fey, W.F. (1954). Acceptance of self and others, and its relation to therapy readiness. Journal of Clinical Psychology, 10(3), 269-271. https://doi.org/ 10.1002/1097-4679(195407)10:3<269::AID JCLP2270100318>3.0.CO;2-E

Hester, W.P. (2012). Cyberbullying intervention: A case study analysis of stakeholder perceptions regarding the authority of school administrators in addressing cyberbullying issues. Dissertation. United States: Ann Arbor. $-156 p$.

Howlett-Brandon, M. (2009) Cyberbullying: an examination of gender, race, ethnicity, and environmental factors from the national crime victimization survey, student crime supplement. Dissertation. Virginia Commonwealth University. $-108 \mathrm{p}$.

Khvan, A.A., Zaitsev, Y.A., Kuznetsova, Y.A. (2006). A standardized questionnaire for measuring aggressive and hostile reactions of $A$. Buss and A. Durkee. Guidelines. - Kemerovo - 66.

König, A., Gollwitzer, M., Steffgen, G. (2010). Cyberbullying as an act of revenge? Australian Journal of Guidance and Counselling, 20(2), 210-224. http://dx.doi. org/10.1375/ajgc.20.2.210

Kowalski, R.M., Giumetti, G.W., Schroeder, A.N., Lattanner, M.R. (2014). Bullying in the digital age: A critical review and meta-analysis of cyberbullying research among youth. Psychological Bulletin, 140. 1073-1137. http://dx.doi.org/10.1037/a0035618

Makarova, E.A., Makarova, E.L., Mahrina, E.A. (2016) Psychological features of cyberbullying as a form of internet crime. Russian psychological journal. M. "Credo", 13(3). 293-313. http://dx.doi.org/10.21702/rpj.2016.3.17

Onur Sezer, G. (2017). The Effect of Compensation Studies on Disadvantaged Children's Bully Behaviours. International Electronic Journal Of Elementary Education, 10(2), 215-223.

Runions, K.C. (2013) Toward a Conceptual Model of Motive and Self-Control in Cyber-Aggression: Rage, Revenge, Reward, and Recreation. Journal of Youth and Adolescence. 42(5). 751-771. https://doi.org/10.1007/ s10964-013-9936-2 
Van Ingen, B.G. (2014) Investigating Entity Theory as a Mediator Between Peer Victimization and Cyberbullying. Dissertation. United States: Ann Arbor. - 151 p.

Vandebosch, H., Van Cleemput, K. (2009) Cyberbullying among youngsters: profiles of bullies and victims. New Media and Society, 11(8), 1349-1371. https://doi. org/10.1177/1461444809341263

Whittaker E., Kowalski R.M. (2015) Cyberbullying Via Social Media. Journal of School Violence, 14(1), 11-29. https: //doi. org/10.1080/15388220.2014.949377

Ybarra, M. L., Mitchell, K. J., Wolak, J., and Finkelhor, D. (2006). Examining characteristics and associated distress related to Internet harassment: Findings from the Second Youth Internet Safety Survey. Pediatrics, 118(4), 1169-1177. https://doi.org/10.1542/peds.2006-0815

Ybarra, M., Mitchell, K., Finkelhor, D., and Wolak, J. (2007). Internet prevention messages: Targeting the right online behaviors. Archives of Pediatrics \& Adolescent Medicine, 161, 138-145. https://doi.org/10.1001/archpedi.161.2.138 